\title{
Sources of omega- 6 fatty acids do not alter the rumen degradation and transit of fibre from dairy cow diets
}

\author{
V.P. Bettero', J.R. Gandra ${ }^{4,5}$, H.V.N. Nunes ${ }^{3}$, J.E. Freitas Jr', R.V. Barletta ${ }^{2}$, M.V. Carvalho², \\ E. Detmann ${ }^{3}$ and J.C. Pereira ${ }^{3}$ \\ ${ }^{1}$ State University of São Paulo, Department of Animal Science, School of Agrarian and Veterinary Science \\ Jaboticabal, Sao Paulo, Brazil \\ ${ }^{2}$ University of Sao Paulo, Department of Animal Nutrition and Production, School of Veterinary Medicine and Animal Science \\ Pirassununga, Sao Paulo, Brazil \\ ${ }^{3}$ Federal University of Viçosa, Department of Animal Science, Viçosa, Minas Gerais, Brazil \\ ${ }^{4}$ Federal University of Great Dourados, Department of Animal Science, School of Agrarian Sciences \\ Rodovia Dourados, Itahum, Km 12, Cidade Universitária, Caixa Postal 533, CEP: 79.804-970, Dourados, Mato Grosso do Sul, Brazil
}

KEY WORDS: dairy cows, neutral detergent fibre, omega-6 PUFA, lipid sources, ruminal kinetics

Received: 10 April 2013

Revised: 27 September 2013

Accepted: 5 November 2013

${ }^{5}$ Corresponding author: e-mail: jeffersongandra@gmail.com

\begin{abstract}
The objective of this study was to evaluate the behaviour of fibre in the digestive tract on the basis of the passage kinetics of forage and concentrate particles in cows fed different omega-6 fatty-acid sources. The scientific hypothesis of this study was that omega-6 fatty acids do not interfere with the digestion of fibre in the diets of dairy cows. Five primiparous lactating Holstein cows were used in the experiment. The experimental diets were: control (C), ground soyabean (GS), cottonseed (CS), soyabean oil (SO), calcium salts of fatty acids (CSFA). The global mean estimates for the parameters of passage rate $(\gamma)$ were 0.038 and $0.055 \mathrm{~h}^{-1}$ for forage and concentrate, respectively. The only significant effect with respect to the passage rate was a high negative correlation between the concentrate passage rate and dry matter intake. There was less undegradable neutral detergent fibre (NDF) in treatments without added lipid. Dietary supplementation with lipid sources does not alter the kinetic parameters of roughage and concentrate particle passage or in vitro NDF degradation. Sources of omega- 6 fatty acids do not alter the rumen degradation and transit of fibre.
\end{abstract}

\section{Introduction}

The effects of unsaturated fatty acids on ruminal digestion may be variable and the amount of roughage used in the diet can be considered a fundamental factor (Ueda et al., 2003). Interactions between degradation rate and passage rate determine the extent of digestion in a compartment and the amount of potentially degradable material in the faeces.
Depending of the type of fatty acid (omega-6 or omega-3) and how it gets into the rumen, free or partially protected, this effect can be maximized or minimized. From the standpoint of rumen carbohydrate fermentation, biohydrogenation is a favourable process because it reduces the potential negative effects of unsaturated fatty acids on rumen fermentation of fibre. The negative effects on microbial fibre digestion are the primary reason why 
large amounts of free vegetable oils cannot be fed to dairy cows (Jalč et al., 2006a).

Unsaturated fatty acids are toxic to many species of rumen bacteria, particularly those that are involved in fibre digestion. Also, because of the anaerobic environment of the rumen, there is an excess of hydrogen that the microbial population continually needs to eliminate (Jalč et al., 2006b).

The objective of this study was to evaluate the behaviour of fibre in the digestive tract by using roughage and concentrate particle transit kinetics, and to evaluate the dynamics of the in vitro neutral detergent fibre degradation of dairy cows receiving diets with different omega-6 fatty acid sources.

\section{Material and methods}

\section{Experiment 1 (in vivo)}

The experiment was conducted in the Dairy Cattle Teaching, Research and Extension Unit of the Animal Science Department of the Viçosa Federal University, Viçosa, MG.

Five lactating primiparous Holstein cows that at the beginning of the experiment were $99 \pm 22$ days in lactation, had $480.4 \pm 2.8 \mathrm{~kg}$ of body weight and a daily milk production of $20.14 \pm 2.23 \mathrm{~kg}$, were used. The animals were housed in tie-stalls. The experimental design was a $5 \times 5$ Latin square. Each experimental period lasted 21 days, of which the first 14 were for adaptation of the animals to the diets and sampling.

Treatments consisted of different dietary lipid sources: 1. control (without lipid supplementation), 2. ground soyabean (GS), 3. cottonseed (CS), 4. soyabean oil (SO), 5. calcium salts of fatty acids (Megalac-E®) (CSFA). The ratio of forage:concentrate was 55:45 on a dry matter (DM) basis; maize silage was used as roughage. All diets were formulated to be isoproteinous according to the NRC (2001). The analysed concentration of omega-6 PUFA of feed was: ground soyabean $(50.18 \%)$, cottonseed (48.76\%), soyabean oil (51.92\%), and calcium salts of fatty acids (E-Megalac $\left.{ }^{\circledR}\right)(34.36 \%)$. Feed intake was controlled daily by weighing the refusals and keeping them between $5 \%$ and $10 \%$ of the total offered (Table 1).

Parameters of the particle passage kinetics were estimated using chromium-mordanted fibre for maize silage, prepared according to Udén et al. (1980), and lanthanum (La) fixed to the soyabean meal fibre, prepared according to Hartnell and Satter (1979). Marked feeds were the same in all treatments. The animals received $75 \mathrm{~g}$ of chromium-marked fibre and $50 \mathrm{~g}$ of lanthanum-marked fibre, orally,
Table 1. Composition of the experimental diets on dry matter basis, $\%$ DM

\begin{tabular}{|c|c|c|c|c|c|}
\hline \multirow{2}{*}{ Indices } & \multicolumn{5}{|l|}{ Diets } \\
\hline & $\mathrm{C}$ & GS & CS & SO & CSFA \\
\hline \multicolumn{6}{|l|}{ Ingredients } \\
\hline maize silage & 55.0 & 55.0 & 55.0 & 55.0 & 55.0 \\
\hline maize grain & 24.7 & 24.0 & 21.0 & 25.0 & 25.0 \\
\hline raw soyabean grain & - & 12.0 & - & - & - \\
\hline soyabean meal & 12.0 & 6.0 & 11.0 & 15.0 & 15.0 \\
\hline calcium salts & - & - & - & - & 2.5 \\
\hline cottonseed & - & - & 10.0 & - & - \\
\hline soyabean oil & - & - & - & 2.00 & - \\
\hline urea/ammonium sulfate $(9: 1)$ & 1.3 & 1.0 & 1.0 & 1.0 & 1.0 \\
\hline wheat meal & 5.0 & - & - & - & - \\
\hline $\begin{array}{l}\text { sodium bicarbonate/ } \\
\text { magnesium oxide }(2: 1)\end{array}$ & 0.4 & 0.4 & 0.4 & 0.4 & 0.4 \\
\hline ADE vitamins & 0.1 & 0.1 & 0.1 & 0.1 & 0.1 \\
\hline mineral mixture ${ }^{1}$ & 1.5 & 1.5 & 1.5 & 1.5 & 1.0 \\
\hline \multicolumn{6}{|l|}{ Chemical composition, $\mathrm{g} \cdot \mathrm{kg}^{-1}$} \\
\hline dry matter ${ }^{2}$ & 587 & 593 & 592 & 589 & 588 \\
\hline organic matter ${ }^{3}$ & 936 & 9.6 & $9.6 \varsigma$ & 934 & 933 \\
\hline crude protein ${ }^{3}$ & 159 & 16.0 & 15.8 & 157 & 157 \\
\hline fat $^{3}$ & 33 & 54 & 5.0 & 51 & 53 \\
\hline neutral detergent fibre ${ }^{3}$ & 380 & 376 & 3953 & 365 & 365 \\
\hline \multicolumn{6}{|l|}{ Fatty acids, $g \cdot 100 \mathrm{~g}^{-1}$ of FA } \\
\hline $\mathrm{C} 14: 0$ & 0.34 & 0.39 & 0.35 & 0.34 & 0.35 \\
\hline $\mathrm{C} 16: 0$ & 15.28 & 15.68 & 13.67 & 15.18 & 15.19 \\
\hline C18:0 & 3.11 & 3.19 & 3.04 & 3.12 & 3.10 \\
\hline $\mathrm{C} 18: 1 \mathrm{cis}$ & 12.33 & 12.47 & 9.86 & 12.56 & 12.70 \\
\hline C18:2 (n-6) & 20.86 & 28.43 & 23.78 & 32.92 & 33.04 \\
\hline C18:3 (n-3) & 2.93 & 2.09 & 1.98 & 2.88 & 2.87 \\
\hline other & 2.74 & 2.83 & 2.67 & 2.71 & 2.88 \\
\hline
\end{tabular}

C - control (without fat source addition); GS - ground soyabean; CS - cottonseed; SO - soyabean oil; CSFA - calcium salts of fatty acids (Megalac-E囚). Dry matter (DM), organic matter (OM), crude protein $(\mathrm{CP})$, ether extract (EE), neutral detergent fibre (NDF); ${ }^{1}$ Composition in $100 \mathrm{~kg}: \mathrm{kg}$ : dicalcium phosphate 42.5, limestone 25 , sodium chloride 21, potassium chloride 7.5 , ammonium sulphate 2.5 , zinc sulphate 1.25 ; g: copper sulphate 250 , cobalt sulphate 15 , sodium selenite $5 ;{ }^{2} \mathrm{~g} \cdot \mathrm{kg}^{-1}$ of natural matter; ${ }^{3} \mathrm{~g} \cdot \mathrm{kg}^{-1}$ of dry matter

at $6.30 \mathrm{~h}$ of the $17^{\text {th }}$ day of each experimental period. Faecal samples were collected directly from the rectum at $0,4,8,12,16,24,30,36,48,56,72,96$ and $120 \mathrm{~h}$ after the administration of the markers. Samples were dried in a forced-air drying oven $\left(60^{\circ} \mathrm{C}\right)$ and ground in a cutting mill to pass a $1 \mathrm{~mm}$ sieve.

Faecal samples used to quantify the kinetic parameters of forage transit were analysed for DM. Chromium levels were determined by atomic absorption spectrophotometry using a nitrous oxide/acetylene flame, a wave length of $398.8 \mathrm{~nm}$, and a gap width of $0.2 \mathrm{~nm}$. In order to obtain the solutions and the readings of the samples containing lanthanum-chelated fibre, a method adapted from Hartnell and Satter (1979) was used. In it, the analysis was done by dry process, in a sand bath $\left(200^{\circ} \mathrm{C}\right)$, using $5 \mathrm{~g}$ of sample in $100 \mathrm{ml}$ crucibles and $6 \mathrm{~N}$ hydrochloric acid for the digestion. 
The parameters of the transit kinetics were estimated by adjusting the gama-2 time-dependent model, described by Ellis et al. (1994), to the faecal excretion of the indicator from each experimental unit:

$$
C_{t}=Z \times(t-\tau) \times \gamma \times \exp [-\gamma \times(t-\tau)]
$$

where: $C_{t}$ - faecal concentration of the indicator in time ' $t$ ' ( $\mathrm{ppm}) ; t$ - time after the indicator administration (h); $\gamma$ - time-dependent rate parameter relating to fibrous particles ruminal flow $\left(\mathrm{h}^{-1}\right) ; Z$ - parameter without direct biological interpretation $(\mathrm{ppm} \times \mathrm{h})$; $\tau$ - time elapsed between the administration and the appearance of the indicator in the faeces (h).

The mean rumen-reticulum retention times were estimated according to Ellis et al. (1994):

$$
\operatorname{RRRT}=\frac{2}{\gamma}
$$

where: RRRT - mean rumen-reticulum retention time (h); $\gamma$ - as previously defined.

\section{Experiment 2 (in vitro)}

In order to evaluate, in vitro, the dynamics of NDF degradation, maize silage aliquots $(192.5 \mathrm{mg}$ of DM) were conditioned in $50 \mathrm{ml}$ glass vials. The concentrates from each of the previously described treatments were then conditioned in the same vials in order to maintain the roughage:concentrate ratio used in the in vivo assay (55:45), making a total of $350 \mathrm{mg}$ of DM per vial. After that, $28 \mathrm{ml}$ of a buffer solution with a $\mathrm{pH}$ of 6.8 previously adjusted by $\mathrm{CO}_{2}$ injection (McDougall, 1949), were added. Vials were kept in an acclimatized room $\left(39^{\circ} \mathrm{C}\right)$ in order to hydrate the samples. During the hydration process, ruminal fluid was collected from a heifer, cannulated in the rumen and kept nearby the incubation room. Ruminal fluid was collected, filtered through a triple layer of gauze, conditioned in a thermos recipient, and immediately transported to the incubation room. Seven milliliters of the ruminal inoculum were added per vial, and immediately after that the incubation environment was saturated with $\mathrm{CO}_{2}$ and the vials were sealed. Vials were kept at $39^{\circ} \mathrm{C}$ under orbital shaking (40 rpm). Fermentation gases were removed every three hours with the aid of needles. Evaluations were done at 0 , $3,6,9,12,24,36,48,72$ and $96 \mathrm{~h}$ of incubation. The incubation procedure was repeated four times, totaling four evaluations per incubation time per treatment. At the end of each incubation time, vials were removed from the acclimatized room and their content was vacuum filtered in filter crucibles (coarse porosity).

Crucibles were conditioned in polyethylene flasks $(120 \mathrm{ml})$, to which $50 \mathrm{ml}$ of neutral detergent were added. After sealing, flasks were autoclaved $\left(105^{\circ} \mathrm{C} / 1 \mathrm{~h}\right)$, in order to extract all neutral detergent soluble components (micro-extraction technique). After that, another vacuum filtration, followed by washing of the residue in hot water and acetone, was done. The residual NDF was obtained after drying the material in an unventilated stove $\left(105^{\circ} \mathrm{C} / 16 \mathrm{~h}\right)$.

The NDF residues in time, for each treatment, were subjected through the PROC NLIN of SAS to an adjustment by the non-linear logistic model:

$$
R t=\operatorname{pdNDF} \times(1+\lambda \times t) \times \exp (-\lambda \times t)+\mathrm{uNDF}
$$

were: $R t$ - undegraded NDF residue in time ' $t$ ' $(\%)$; pdNDF - potentially degradable NDF fract ion (\%); uNDF - undegradable NDF fraction (\%); $\lambda$ - combined fractional rate of latency and degradation of the pdNDF $\left(\mathrm{h}^{-1}\right) ; t$ - time (h).

Because parameter $\lambda$ represents latency and degradation rates together, the fractional degradation rate was estimated from $\lambda$ using the gama- 2 distribution properties (Ellis et al., 1994):

$$
k d=0.59635 \times \lambda
$$

where: $k d$ - fractional degradation rate of the $\operatorname{pdFDN}\left(\mathrm{h}^{-1}\right)$.

The estimates of the discrete latency were obtained according to the derivations from Vieira et al. (1997):

$$
L=\frac{R(0)-R\left(t_{i}\right)+t_{i}}{R^{\prime}\left(t_{i}\right)}
$$

where: $L$ - discrete latency (h); $R(0)$ - undegraded NDF residue in $t-0(\%) ; R\left(t_{i}\right)$ - undegraded NDF residue obtained at the inflection point of the degradation curve $(\%) ; R^{\prime}\left(t_{i}\right)$ - derived of the degradation-adjusted curve to the inflection point (maximum degradation rate of the substrate) $\left(\mathrm{h}^{-1}\right)$; $t_{i}$ - time equivalent to the inflection point of the degradation curve (h).

The $t_{i}$ values were obtained according to Van Milgen et al. (1991):

$$
t_{i}=\frac{1}{\lambda}
$$

The effectively degraded fractions of the NDF were obtained through an adaptation of the Ørskov and McDonald (1979) suggestions, according to the equation:

$$
\mathrm{EDF}=\lim _{t \rightarrow \infty} \int_{0}^{t} f\left(-\frac{d R T}{d t}\right) d t
$$

where: EDF - effectively degraded fraction of the NDF (\%); $f$ - function relative to the movement of the solids in the ruminal environment.

In order to define the function above (7), a ruminal movement of solids of gamma-1 order was assumed, according to the equation: 


$$
f=\exp (-k \times t)
$$

where: $k$ - fractional rate of solids movement in the ruminal environment $\left(\mathrm{h}^{-1}\right)$, which was obtained by weighing the passage rates of roughage solids and concentrate from the in vivo assay as a function of the participation of each one in the total diet NDF.

Thus, the effectively degraded fraction was estimated as:

$$
\mathrm{EDF}=\operatorname{pdNDF} \times \frac{\lambda^{2}}{(\lambda+k)^{2}}
$$

\section{Statistical analyses}

The non-linear adjustments were done by the Gauss-Newton interactive algorithm in PROC NLIN of the SAS programme (Statistical Analysis System, version 9.2). Parameters $\gamma$ and RRRT estimates were compared by variance analysis according to a $5 \times 5$ Latin square design, considering treatment and experimental period as fixed effects, and animal as a variable effect. Data were analysed with PROC MIXED of SAS. Pearson's linear correlation coefficients were estimated for transit kinetics and intake and production characteristics. Estimates were obtained in an adjusted form for the effects of animal and experimental period by the MANOVA routine, implemented in PROC GLM of SAS.

\section{Results}

\section{Productive performance}

The level of supplementation was insufficient to promote significant changes in the fat content of milk (\%). The daily milk yield in $\mathrm{kg}$ per day was higher $(P<0.05)$ in animals supplemented with CSFA in relation to those supplemented with $\mathrm{SO}$ and $\mathrm{C}$. There was no difference $(P>0.05)$ among treatments for DM and NDF intake. The fat intake was higher $(P<0.05)$, however, for diets

Table 2. Productive performance of lactating dairy cows fed diets with

\begin{tabular}{|c|c|c|c|c|c|c|c|}
\hline \multirow{2}{*}{ Item } & \multicolumn{5}{|c|}{ Experimental diets } & \multirow{2}{*}{-SEM } & \multirow{2}{*}{$P$} \\
\hline & $\mathrm{C}$ & GS & CS & SO & CSFA & & \\
\hline \multicolumn{8}{|c|}{ Intake, kg per day } \\
\hline DM & 17.09 & 17.10 & 16.59 & 16.73 & 17.10 & 0.78 & 0.932 \\
\hline NDF & 6.04 & 5.78 & 6.07 & 5.71 & 5.16 & 0.26 & 0.066 \\
\hline fat & $0.43^{b}$ & $0.73^{a}$ & $0.72^{\mathrm{a}}$ & $0.71^{\mathrm{a}}$ & $0.71^{\mathrm{a}}$ & 0.04 & 0.001 \\
\hline \multicolumn{8}{|c|}{ Yield, kg per day } \\
\hline milk & $18.48^{b}$ & $19.89^{\mathrm{ab}}$ & $19.08^{\mathrm{ab}}$ & $18.70^{b}$ & $21.90^{\mathrm{a}}$ & 2.46 & 0.023 \\
\hline FCM, 3.5\% & 19.29 & 18.23 & 19.84 & 19.54 & 21.21 & 2.42 & 0.422 \\
\hline Percentage & & & & & & & \\
\hline fat & 3.78 & 3.19 & 3.77 & 3.74 & 3.32 & 0.22 & 0.187 \\
\hline
\end{tabular}
different lipid sources supplemented with lipids compared with the control treatment, with no difference among the experimental diets due to the characteristics of the treatments (Table 2). The performance data were used in this article only to emphasize the Pearson correlation analysis (Table 4) that is discussed in a subsequent article.

\section{Ruminal kinetics}

The ruminal passage of solids from the roughage or the concentrate fractions did not differ among diets $(P>0.05)$. The global mean estimate of the time-dependent rate $(\gamma)$ parameter was 0.038 and $0.055 \mathrm{~h}^{-1}$, for roughage (chromium) and concentrate (lanthanum), respectively. Despite the numerical differences, the retention time in the rumen-reticulum also did not differ among diets $(P>0.05)$, and averaged 52.84 and $38.15 \mathrm{~h}$ for roughage and concentrate, respectively (Table 3 ).

Table 3. Estimates of fibre transit kinetics parameters in lactating cows

\begin{tabular}{|c|c|c|c|c|c|c|}
\hline \multirow{2}{*}{ Indices } & \multicolumn{5}{|c|}{ Treatments } & \multirow{2}{*}{$P$} \\
\hline & $\mathrm{C}$ & GS & CS & SO & CSFA & \\
\hline \multicolumn{7}{|c|}{ Roughage } \\
\hline V & $\begin{array}{l}0.041 \\
\pm 0.002\end{array}$ & $\begin{array}{l}0.037 \\
\pm 0.002\end{array}$ & $\begin{array}{l}0.036 \\
\pm 0.002\end{array}$ & $\begin{array}{l}0.038 \\
\pm 0.002\end{array}$ & $\begin{array}{l}0.040 \\
\pm 0.002\end{array}$ & 0.363 \\
\hline RRRT & $\begin{array}{l}48.8 \\
\pm 2.99\end{array}$ & $\begin{array}{l}56.1 \\
\pm 2.99\end{array}$ & $\begin{array}{l}56.3 \\
\pm 2.99\end{array}$ & $\begin{array}{l}53.5 \\
\pm 2.99\end{array}$ & $\begin{array}{l}49.5 \\
\pm 2.99\end{array}$ & 0.250 \\
\hline \multicolumn{7}{|c|}{ Concentrate } \\
\hline V & $\begin{array}{l}0.058 \\
\pm 0.005\end{array}$ & $\begin{array}{l}0.055 \\
\pm 0.005\end{array}$ & $\begin{array}{l}0.051 \\
\pm 0.005\end{array}$ & $\begin{array}{l}0.054 \\
\pm 0.007\end{array}$ & $\begin{array}{l}0.055 \\
\pm 0.005\end{array}$ & 0.902 \\
\hline RRRT & $\begin{array}{l}34.7 \\
\pm 4.31\end{array}$ & $\begin{array}{l}36.8 \\
\pm 4.31\end{array}$ & $\begin{array}{l}41.2 \\
\pm 4.31\end{array}$ & $\begin{array}{l}40.6 \\
\pm 6.08\end{array}$ & $\begin{array}{l}36.6 \\
\pm 4.31\end{array}$ & 0.722 \\
\hline
\end{tabular}
fed diets with different lipid sources

$y$ - time-dependent rate-parameter relative to the ruminal flow of fibrous particles $\left(h^{-1}\right)$; RRRT - average rumen-reticulum retention time; C - control (without fat source addition); GS - ground soyabean; CS - cottonseed; SO - soyabean oil; CSFA - calcium salts of fatty acids (Megalac-E®)

Table 4. Pearson's linear correlation coefficients among variables: dry matter intake (DMI); neutral detergent fibre intake (NDFI), 3.5\% fatcorrected milk production (CMP - kg per day); milk fat percentage $(\mathrm{F}-\%)$; time-dependent rate-parameter relative to the ruminal flow of roughage particles $\left(\mathrm{ycr}-\mathrm{h}^{-1}\right)$ and time-dependent rate-parameter

\begin{tabular}{|c|c|c|c|c|c|}
\hline \multirow{2}{*}{ Variable $e^{1,2}$} & \multicolumn{5}{|c|}{ Variable $^{1,2}$} \\
\hline & $\overline{\mathrm{DMl}}$ & $F$ & CMP & $V_{C R}$ & $V_{L A}$ \\
\hline \multirow{2}{*}{ NDFI } & 0.441 & 0.028 & -0.419 & -0.270 & -0.370 \\
\hline & 0.099 & 0.920 & 0.119 & 0.328 & 0.174 \\
\hline \multirow{2}{*}{ DMI } & & -0.026 & -0.017 & 0.065 & -0.561 \\
\hline & - & 0.924 & 0.951 & 0.815 & 0.029 \\
\hline \multirow{2}{*}{$F$} & & & 0.556 & -0.033 & -0.186 \\
\hline & & - & 0.031 & 0.905 & 0.507 \\
\hline \multirow{3}{*}{ CMP } & & & & 0.048 & -0.105 \\
\hline & & & - & 0.864 & 0.708 \\
\hline & & & & & 0.207 \\
\hline$V_{C R}$ & & & & - & 0.457 \\
\hline
\end{tabular}
relative to the ruminal flow of concentrate particles $\left(y / a-h^{-1}\right)$

${ }^{1}$ subscribed values correspond to descriptive levels of probability for type I error associated to the hypothesis: $h_{:}: \rho=0 ; \rho \neq 1$. 2 The correlation coefficients were adjusted for effects of animal and experimental period 
Diet CS had the lowest numerical passage rate value, although not showing a significant effect. Diets CS and GS also showed numerically greater retention times in the rumen. The kinetic values found with the use of calcium salts, in this study, were the closest to the control diet. Concerning the treatment without added lipid supplement, the passage rate values were $0.0583 \mathrm{~h}^{-1}$ and $0.0412 \mathrm{~h}^{-1}$ for concentrate and roughage, respectively (Table 3 ).

Generally, the roughage $\left(\gamma_{c r}\right)$ and concentrate $\left(\gamma_{l a}\right)$ passage rates had similar non-significant associations in relation to the NDF intake and $F$ variables. The only significant effect, regarding the passage rate, was a high negative correlation $(P<0.05)$ between the concentrate passage rate $\left(\gamma_{l a}\right)$ and the DMI (Table 4).

\section{In vitro degradation of $\mathrm{NDF}$}

There were no differences $(P>0.05)$ in the potentially degradable fraction of NDF (pdNDF), although the values obtained for the supplemented diets (GS, CS and SO) were, respectively, $12.69 \%, 5.59 \%$ and $11.07 \%$ lower, compared with the unsupplemented diet, except the CSFA diet, which had a degradation $2.93 \%$ higher than the control (Table 5).

The effectively degraded fraction $\left(\mathrm{EDF}_{\mathrm{t}}\right)$ also did not differ among diets $(P>0.05)$, although the numerical values of diets GS, CS and SO were, respectively, $6.41 \%, 8.64 \%$ and $7.49 \%$ lower compared with the control diet, and $2.93 \%$ higher than diet CSFA (Table 4). The common rate of latency and degradation was also considered similar for all diets. Diets without lipid supplementation and with calcium salts had lower NDF undegradable fractions (I) $(38.47 \%$ and $36.61 \%$, respectively) than the others. The values for treatments GS, CS and SO were, respectively $16.88 \%, 8.21 \%$ and $15.04 \%$ higher than C.

Table 5. Percentage estimates of the potentially degradable fraction of the NDF (b), indegradable fraction of the NDF (i), effectively degraded fraction in relation to the total diet NDF $\left(E_{D F}\right)$, and of the common fractional rate for latency and degradation $\left(\lambda-h^{-1}\right)$ and of the discrete latency rate for degradation of the NDF $(L A G-h)$ for degradation profiles adjusted for different treatments

\begin{tabular}{llllll}
\hline \multirow{2}{*}{ Treatment } & \multicolumn{5}{l}{ Parameter } \\
\cline { 2 - 6 } & $\mathrm{b}$ & $\mathrm{i}$ & $\lambda$ & EDFt & LAG \\
\hline C & $61.5 \pm 3.12$ & $38.5 \pm 2.62$ & $0.08 \pm 0.009$ & 46.1 & 3.2 \\
GS & $53.7 \pm 2.93$ & $46.3 \pm 2.38$ & $0.09 \pm 0.011$ & 43.1 & 2.9 \\
CS & $58.1 \pm 3.18$ & $41.9 \pm 2.90$ & $0.07 \pm 0.008$ & 42.1 & 3.9 \\
SO & $54.7 \pm 3.11$ & $45.3 \pm 2.58$ & $0.09 \pm 0.011$ & 42.6 & 3.1 \\
CSFA & $63.4 \pm 3.14$ & $36.6 \pm 2.77$ & $0.08 \pm 0.008$ & 46.9 & 3.4 \\
$P$ & 0.115 & 0.030 & 0.540 & - & - \\
\hline
\end{tabular}

C - control (without fat source addition); GS - ground soyabean; CS - cottonseed; SO - soyabean oil; CSFA - calcium salts of fatty acids (Megalac-E®)

\section{Discussion}

\section{Ruminal kinetics}

The passage rate of feed in the rumen is a variable of great importance, for it determines the digesta flow through the digestive tract. Greater passage rates are observed in highly digestible diets, with high daily intakes, and which are provided with greater frequency per day.

Because the roughage used in the different treatments was of the same kind and on the same level, and concentrates had a homogenous grinding pattern, except for the cottonseed that was provided whole and thus had greater particle size, no differences in passage rates were expected due to particle size. The amount of cottonseed required to keep the diets within the desired fat levels did not influence the particle passage rate.

The retention time in the rumen, calculated by the reciprocal passage rate in the organ, is correlated with the feeding level of the animal, as higher intakes result in greater passage rates and, consequently, higher nutrient supplies to the animal. The DM intake was relatively constant, however, and remained within normal limits for the evaluated animal category and production level.

The greater the degree of unsaturation of the fatty acid chain, the greater may be their interference in the kinetics of fibre in the gastrointestinal tract dueto the decreased rate of passage that may be affected by decreased digestibility resulting from a possible deleterious action of some sources of fatty acids in the rumen (Jenkins, 1993).

Higher forage levels in the diet increase the ruminal retention time due to the slower fibre degradation rate, and higher amounts of fibre in the intestines reduce the post-ruminal retention time by stimulating peristalsis. Although the treatments had similar fibre levels, the origin and behaviour of this fibre differed according to the fatty-acid source utilized, especially relating to the cottonseed treatment. This may affect the RRRT when higher levels of lipid supplements are provided.

Costa (2008), evaluating lipid sources (control, soyabean, soyabean with formaldehyde, soyabean oil and calcium salts), also observed no difference $(P>0.05)$ in passage rates and RRRT among diets for roughage and soyabean meal particles. The mean values were 0.052 and $0.064 \mathrm{~h}^{-1}$, for maize silage (chromium) and soyabean meal (ytterbium), respectively. Maize silage RRRT was $38.68 \mathrm{~h}$ and soyabean meal RRRT was $25.3 \mathrm{~h}$.

The results observed for the CS diet can be explained by the presence of the cottonseed lint, 
which decreases the passage rate, altering ruminal fill and stimulating chewing, which contributes to increased digestibility. The lower roughage passage rate of GS diet, compared with the other diets, can be explained by the high hemicellulose content and by the cell wall structural characteristics of the oilseeds, in which the paired epidermis cells contribute to this increase in the length of the time of permanence, reducing digestibility and diet energy. Therefore, it is suggested that the peculiar characteristics of oilseeds are taken into account when used in their integral form.

Cecava and Parker (1993), working with steers fed maize silage and concentrate at a proportion of 62:38, observed a concentrate particle (ytterbium marked) passage rate of $0.0686 \mathrm{~h}^{-1}$, close to that received by Bürger et al. (2000) under similar conditions, of $0.0679 \mathrm{~h}^{-1}$ for soyabean meal and $0.0412 \mathrm{~h}^{-1}$ for chromium-marked maize silage, higher than the values reported in this study with lanthanum, but similar to that observed for chromium.

Campos et al. (2007) suggested that the ruminal passage rates for forages are around $0.0416 \mathrm{~h}^{-1}$, close to the average of the treatment without lipid addition in the present study. In the same way, the discrepancies between the values of $\gamma$ and RRRT, in particular, found between the present study and those in the literature, demonstrate the need to obtain more research data on ruminal kinetics, in order to predict the mean disappearance of feed in the rumen in a more adequate form.

All diets contained the same concentration of fibre or NDF and similar fat concentrations, except the control diet, the only factor that could influence the degradation and kinetics of fibre would be the unsaturation of fatty acids of the various sources used, due the toxicity of these sources to fibredegrading bacteria. The sources of omega- 6 were not able, however, to affect the process of ruminal digestion, due to the low degree of unsaturation of these sources. This same result could be different if the supplementation was with sources of omega-3 fatty acids, such as fish oil and linseed, due to the high degree of unsaturation and the size of these fatty-acid chains.

\section{In vitro degradation of the $\mathrm{NDF}$}

The effective degradation of the NDF, although not statistically different, indicates that omega-6 fatty acid utilization may affect fibre degradability when used in ruminant diets at levels higher than the ones in this study, and that lipid protection through the formation of calcium salts of fatty acids is efficient in decreasing this degradation.
Firkins et al. (1991), evaluating the in vitro fibre degradation, observed that addition of soyabean oil at $10 \%$ did not affect NDF digestion. Possibly, the small particle size and large surface area of the cellulose used as the fibre source may have dispersed the fat enough to avoid inhibition of NDF digestion by the active surface properties of fatty acids, since according to other studies, supplementation in this level affects fibre degradation.

Supplementation of diets of dairy cows with sources of omega- 6 fatty acids does not really affect NDF degradability because it alters the basal ruminal fermentation as evidenced by Cieślak et al. (2013). The same authors conclude emphatically that supplementation with sources of omega- 6 fatty acids did not adversely alter ruminal fermentation and, therefore, so also do not alter the degradation of NDF, which can no longer be said to be sources of omega-3 fatty acids.

Similar results were also obtained by Szumacher-Strabel et al. (2009), who observed no change in the concentrations of acetate and propionate when sources of omega- 6 fatty acids were inoculated in the rumen of dairy cows, also indicating that there is no interference in the digestibility of NDF in these cases.

The release of omega- 6 fatty acids from oilseeds is slow, providing small amounts of lipids in the ruminal environment, which may result in rapid biohydrogenation, avoiding unsaturated fatty acid accumulation and impairment of the ruminal degradation of the fibre. Moreover, the amount will not be enough to adhere to feed particles, causing physical impediment to microorganisms and microbial enzymes.

\section{Conclusions}

Inclusions of sources of omega- 6 fatty acids do not interfere with digestion and kinetics of fibre in dairy cows in mid-lactation. Further studies should be performed in order to determine the behaviour of the fibre when cows are supplemented with sources of omega-3, as well as to establish digestion parameters in dairy cows in early lactation and the transition period, when supplemented with omega-3 and omega- 6 fatty acids.

\section{References}

Bürger P.J., Pereira J.C., Queiroz, A.C., 2000. Feeding behavior in Holstein calves fed diets with different concentrate levels. R. Bras. Zootec. 72, 236-242

Campos W.E., Benedetti E., Rodríguez N.M., 2007. Cinética ruminal de vacas leiteiras a pasto consumindo diferentes gramíneas tropicais. Arch. Zootec. 56, 829-837 
Cecava M.J., Parker J.E., 1993. Intestinal supply of amino acids in steers fed ruminally degradable and undegradable crude protein sources alone and in combination. J. Anim. Sci. 71, 1596-1605

Cieślak A., Váradyová Z., Kišidayová S., Jalč D., Szumacher-Strabel M., 2013. Effect of diets with fruit oils supplements on rumen fermentation parameters, fatty acid composition and methane production in vitro. J. Anim. Feed Sci. 22, 26-34

Costa M.G., 2008. Diets with diferentes lipids sources for dairy cow. (in Spanish). Ph.D. Thesis - Animal Science - UFV, ViçosaMG, pp. 119

Ellis W.C., Matis J.H., Hill T., Murphy M.R., 1994. Methodology for estimating digestion and passage kinetics of forages. In: G.C. Fahey, M. Collins, D.R. Mertens, L.E. Moser (Editors). Forage Quality, Evaluation, and Utilization. Madison WI: Amer. Soc. Agron., pp. 682-756

Firkins J.L., Bowman J.G.P., Weiss W.P., Naderer J., 1991. Effects of protein, carbohydrate, and fat sources on bacterial colonization and degradation of fibre in vitro. J. Anim. Sci. 74, 4273-4283

Hartnell G.F., Satter L.D., 1979. Extent of particulate marker (samarium, lanthanum and cerium) movement from one digesta particle to another. J. Anim. Sci. 48, 375-380

Jalč D., Potkański A., Szumacher-Strabel M., Kowalczyk J., Cieślak A., 2006a. The effect of a high concentrate diet and different fat sources on rumen fermentation in vitro. J. Anim. Feed Sci. 15, Suppl. 1, 137-140

Jalč D., Potkański A., Szumacher-Strabel M., Kowalczyk J., Cieślak A., 2006b. The effect of a high forage diet and different oil blends on rumen fermentation in vitro. J. Anim. Feed Sci. 15 Suppl. 1, 141-144
Jenkins T.C., 1993. Lipid metabolism in the rumen. J. Dairy Sci. 76, 3851-3863

McDougall E.I., 1949. Studies on ruminal saliva. 1. The composition and output of sheep's saliva. Biochem. J. 43, 99-109

Mertens D.R., 2002. Gravimetric determination of amylase-treated neutral detergent fibre in feeds with refluxing beakers or crucibles: collaborative study. J. AOAC 85, 1217-1240

NRC, 2001. Nutrient of Requirements of Dairy Cattle. $7^{\text {th }}$. Edition. National Academic Press. Washington, DC

Ørskov E.R., McDonald I., 1979. The estimation of protein degradability in the rumen from incubation measurements weighted according to rate of passage. J. Agr. Sci. 92, 499-503

Szumacher-Strabel M., Cieślak A., Nowakowska A., 2009. Effect of oils rich in linoleic acid on in vitro rumen fermentation parameters of sheep, goats and dairy cows. J. Anim. Feed Sci. 18, 440-452

Udén P., Colucci P.E., Van Soest P.J., 1980. Investigation of chromium, cerium and cobalt as markers in digesta. Rate of passage studies. J. Sci. Food Agr. 31, 625-632

Ueda K., Ferlay A., Chabrot J., 2003. Effect of linseed oil supplementation on ruminal digestion in dairy cows fed diets with different forage:concentrate ratios. J. Dairy Sci. 86, 3999-4007

Van Milgen J., Murphy L.L., Berger L.L., 1991. A compartmental model to analyze ruminal digestion. J. Dairy Sci. $74,2515-2529$

Vieira R.A.M., Pereira J.C., Malafaia P.A.M., Queiroz de A.C., 1997. Application of non-linear models in the description of in situ degradation profiles of the elephant grass (Pennisetum purpureum Schum., Mineiro variety). Anim. Feed Sci. Tech. 66, 197-210 